\title{
Molecular implications of MUC5AC-CD44 axis in colorectal cancer progression and chemoresistance
}

\author{
Ramesh Pothuraju', Satyanarayana Rachagani', Shiv Ram Krishn ${ }^{1 \dagger}$, Sanjib Chaudhary ${ }^{1 \dagger}$, \\ Rama Krishna Nimmakayala ${ }^{1}$, Jawed A. Siddiqui ${ }^{1}$, Koelina Ganguly ${ }^{1}$, Imayavaramban Lakshmanan ${ }^{1}$, Jesse L. Cox ${ }^{2}$, \\ Kavita Mallya ${ }^{1}$, Sukhwinder Kaur ${ }^{1}$ and Surinder K. Batra ${ }^{1,2,3,4^{*}}$ (D)
}

\begin{abstract}
Background: Differential expression of mucins has been associated with several cancers including colorectal cancer (CRC). In normal physiological conditions, secretory mucin MUC5AC is not expressed in the colonic mucosa, whereas its aberrant expression is observed during development of colon cancer and its precursor lesions. To date, the molecular mechanism of MUC5AC in CRC progression and drug resistance remains obscure.

Methods: MUC5AC expression was determined in colon tissue microarray by immunohistochemistry. A RNA interference and CRISPR/Cas9-mediated system was used to knockdown/knockout the MUC5AC in CRC cell lines to delineate its role in CRC tumorigenesis using in vitro functional assays and in vivo (sub-cutaneous and colon orthotopic) mouse models. Finally, CRC cell lines and xenograft models were used to identify the mechanism of action of MUC5AC.

Results: Overexpression of MUC5AC is observed in CRC patient tissues and cell lines. MUC5AC expression resulted in enhanced cell invasion and migration, and decreased apoptosis of CRC cells. MUC5AC interacted with CD44 physically, which was accompanied by the activation of Src signaling. Further, the presence of MUC5AC resulted in enhanced tumorigenesis and appearance of metastatic lesions in orthotopic mouse model. Additionally, upregulation of MUC5AC resulted in resistance to 5 -fluorouracil (5-FU) and oxaliplatin, and its knockout increased sensitivity to these drugs. Finally, we observed that up-regulation of MUC5AC conferred resistance to 5-FU through down-regulation of p53 and its target gene p21 and up-regulation of $\beta$-catenin and its target genes CD44 and Lgr5.

Conclusion: Our findings suggest that differential expression of secretory mucin MUC5AC results in enhanced tumorigenesis and also confers chemoresistance via CD44/ $\beta$-catenin/p53/p21 signaling.
\end{abstract}

Keywords: Mucins, MUC5AC, CD44, $\beta$-Catenin, Colon cancer, Colorectal cancer, 5'-fluorouracil, Chemoresistance

\section{Background}

Colorectal cancer (CRC) is the most commonly diagnosed cancer and the third leading cause of cancerrelated deaths [1]. Mucins are high molecular weight glycoproteins involved in protection of the epithelial linings of different organs from physical, chemical and

\footnotetext{
* Correspondence: sbatra@unmc.edu

†Shiv Ram Krishn and Sanjib Chaudhary contributed equally to this work.

'Department of Biochemistry and Molecular Biology, University of Nebraska Medical Center, Omaha, NE, USA

${ }^{2}$ Department of Pathology and Microbiology, University of Nebraska Medical Center, Omaha, NE, USA

Full list of author information is available at the end of the article
}

pathogenic insults [2]. Mucin expression is tissue specific, however, their aberrant expression is observed in multiple malignancies. Differential expression of mucins has been associated with tumor cell proliferation, migration, invasion, adhesion, and metastasis [3, 4]. In addition, alteration of mucin expression and glycosylation pattern have strongly been associated with development of CRC [3]. Interestingly, secreted mucins MUC5AC and MUC6 are not expressed in normal colonic mucosa, but both are expressed during CRC progression [2]. Development of CRC is also accompanied by loss of conventional colonic mucin MUC2 and 
appearance of gastric mucin MUC5AC. Loss of MUC2 expression in colon adenocarcinoma has been strongly associated with poor prognosis in stage II and III CRC patients [5]. Further studies suggest that loss of MUC2 contributes to cancer invasion and metastasis through interleukin-6 signaling [6,7]. Under normal conditions, expression of secretory mucin MUC5AC is restricted to stomach, lungs, ear, conjunctiva, nasopharynx, and gallbladder. Although MUC5AC expression is absent in normal colon, its expression increases across benign and malignant conditions [8]. Krishn et al. (2016) observed the down-regulation of MUC2 and MUC4, and overexpression of MUC1 and MUC5AC in colonic polyps, adenomas and CRC [3]. Additionally, MUC5AC alone or in combination with CA19-9 emerged as a potential marker to discriminate pancreatic cancer from chronic pancreatitis [9]. However, to date the molecular mechanism of MUC5AC in CRC progression and drug resistance remains obscure.

Cancer cells which express certain type of mucins (MUC1, 4, 5 AC, 6, 13, 16 and 20) are resistant to chemotherapeutic drugs due to the physiological mucin barrier, drug efflux proteins, resistance to apoptosis, stem cells, and transition from epithelial to mesenchymal phenotype $[10,11]$. Considering differential expression of mucins during disease development and chemoresistance, the present study explores the functional and mechanistic role of MUC5AC in CRC progression and chemoresistance. We observed physical interaction of MUC5AC with CD44 and direct impact of MUC5AC on Src signaling. Upregulation of MUC5AC expression was observed upon 5-fluorouracil (5-FU) treatment, and inhibition of MUC5AC enhanced tumor cells sensitivity to 5-FU. The resistance to 5-FU is due to down-regulation of p53 and its target molecule p21, which results in inhibition of drug-induced apoptotic cell death. Importantly, decreased expression of p53 occurs via activation of the $\beta$-catenin pathway and up-regulation of its target genes CD44 and Lgr5.

\section{Methods}

\section{Cell lines and culture}

Human colorectal cancer cell lines (HCT-8 and LS174T) and normal colon cell line (CCD $841 \mathrm{CoN}, \mathrm{ATCC}^{\circ}$ $\mathrm{CRL}_{1790^{\mathrm{mm}}}$ ) were obtained from American Type Culture Collection and cultured in DMEM and MEM supplemented with $10 \%$ fetal bovine serum (FBS) and antibiotics $(100 \mathrm{U} / \mathrm{ml}$ penicillin and $0.1 \mathrm{mg} / \mathrm{ml}$ streptomycin) at $37^{\circ} \mathrm{C}$ with $5 \% \mathrm{CO}_{2}$ in a humidified atmosphere. Both HCT-8 and LS174T cell lines have mutant KRAS and wild-type TP53 [12, 13]. All the cell lines were tested for mycoplasma contamination before use and validated by short tandem repeat profiling.

\section{Gene silencing by shRNA or siRNA transfection}

For stable transfection, endogenous MUC5AC expression was silenced by a small hairpin RNA construct (pSUPER-Retro-shMUC5AC) as mentioned previously [14]. Briefly, scrambled and shMUC5AC constructs were transfected with Lipofectamine 2000 (Invitrogen, CA, USA) into phoenix cells and incubated for $48 \mathrm{~h}$. Later, retrovirus titer in culture supernatant was collected and incubated in a six-well plate containing colon cell lines in the presence of hexadimethrine bromide (polybrene). After $48 \mathrm{~h}$, positively infected cells were selected using puromycin at $4 \mu \mathrm{g} / \mathrm{ml}$. In case of CD44 transient silencing, we used ON-TARGETplus human CD44 siRNA at $80 \mathrm{nM}$ (Dharmacon, Illinois, USA) according to the manufacturer's instructions.

\section{Western blot analysis}

Total protein lysates were prepared in radio immunoprecipitation assay (RIPA) lysis buffer containing $50 \mathrm{mM}$ Tris- $\mathrm{HCl}, 150 \mathrm{mM} \mathrm{NaCl}, 1 \% \mathrm{NP}-40,0.5 \%$ sodium deoxycholate, $0.1 \%$ sodium dodecyl sulfate along with protease inhibitor cocktail (Roche Diagnostics, Mannheim, Germany). Proteins (concentration from 20 to $40 \mu \mathrm{g}$ ) were resolved in 10-12\% sodium dodecyl sulfate-polyacrylamide gel electrophoresis. Due to its high molecular weight, MUC5AC was resolved in 2\% SDS-agarose gel. Blotting was done from gel to polyvinylidene difluoride (PVDF) membranes, and the membrane was blocked for $1 \mathrm{~h}$ in $5 \%$ non-fat dry milk having phosphate-buffered saline with $0.1 \%$ Tween 20 (PBST). After blocking, membranes were washed with PBST and incubated with primary antibodies at $4{ }^{\circ} \mathrm{C}$ overnight. Further, membranes were washed in PBST (3 times, $10 \mathrm{~min}$ each) then probed with respective secondary antibodies for $1 \mathrm{~h}$ at room temperature (RT) and visualized with a chemiluminescence reagent (GE Healthcare Bio-Sciences, PA, USA). The following antibodies from various vendors were used for immunoblotting studies: MUC5AC (Millipore \#MAB2011, MA, USA), anti-pSrc ${ }^{\text {Y416 }}$ (Cat. \#2101), Src (Cat. \#2108), anti-CD44 (Cat. \#3570), cleaved PARP (Cat. \#9542), cleaved caspase 9 (Cat. \#20750), p21 (Cat. $\# 2947$ ) and $\beta$-catenin (Cat. \#19807), pAKT ${ }^{\mathrm{S} 473}$ (Cat. \#4060), AKT (Cat. \#2920), Lrp6 (Cat. \#2560), and CD133 (Cat. \#5860) from Cell signaling Technology Inc. (MA, USA); paxillin (sc-365,174), p53 (sc-126), Chk1 (sc-8408), and $\beta$-actin $(\mathrm{sc}-47,778)$ from Santa Cruz Biotechnology Inc. (CA, USA); anti-integrin $\beta 4$ (Cat. \#ab29042) from Abcam (MA, USA); Lgr5 (Cat. \#PA549691) from ThermoFisher Scientific (NY, USA); and MUC4 (8G7; generated in-house) [15].

\section{RNA isolation and real-time PCR}

Total RNA was isolated from colon cell lines by using Qiagen Kit (Germantown, MD), and 2000 ng of RNA 
was used for the cDNA synthesis by using reverse transcriptase SuperScript ${ }^{\circ}$ II (Invitrogen, CA, USA). SYBR Green was used for real-time PCR detection and normalized with $\beta$-actin. All samples were analyzed in triplicate and the data were calculated according to the $2^{-\Delta \Delta C T}$ method.

\section{Immunofluorescence}

For immunofluorescence, HCT-8 and LS174T cells with scrambled (Scr) vector control or MUC5AC knockdown (Sh5AC) were seeded $(10,000$ cells/well) in a six-well plate having sterilized cover slips and incubated for $48 \mathrm{~h}$. After that, cells were washed in Hanks buffer solution (2 times, $5 \mathrm{~min}$ each), fixed in ice-cold methanol $\left(-20^{\circ} \mathrm{C}\right)$ for $2 \mathrm{~min}$ and washed in PBS $\left(2 \times 5^{\prime}\right.$ each). Cells were then blocked with $10 \%$ normal goat serum (Jackson Immunoresearch Labs, Inc., PA, USA) for $1 \mathrm{~h}$, exposed to primary antibody (MUC5AC 1:500, Millipore sigma, USA) after PBS wash and kept at $4{ }^{\circ} \mathrm{C}$ overnight. Fluorescein isothiocyanate-conjugated anti-mouse (1:400, ThermoFisher Scientific, NY, USA) secondary antibody was added to the cells followed by $1 \mathrm{~h}$ incubation at RT. Finally, cells were washed with PBS $\left(4 \times 5^{\prime}\right.$ each), and coverslips with adhered cells were carefully inverted on top of the microscopic slides containing anti-fade Vectashield mounting medium (Vector Laboratories, Burlingame, CA, USA) along with 4',6-diamidino-2phenylindole (DAPI) for Laser confocal microscopy by using an LSM 510 microscope (Carl Zeiss GmbH, Germany).

\section{Cell proliferation and colony formation assay}

Sh5AC or Scr cells were seeded (5000 cells/well) in 96well plates containing DMEM, 1\% FBS with puromycin selection, and MTT assay was performed for six days. Each day, MTT reagent was added and incubated for $4 \mathrm{~h}$ followed by dissolving formazan crystals in DMSO, and absorbance was recorded. For colony formation assay, approximately 2500 cells were seeded in a six-well plate, after 15-18 days cells were stained with crystal violet, further dissolved in $10 \%(\mathrm{v} / \mathrm{v})$ acetic acid, and absorbance was recorded at $590 \mathrm{~nm}$ [16].

\section{Cell migration and invasion assays}

Both Scr or Sh5AC cells $\left(1 \times 10^{6}\right)$ were seeded on top of a Boyden Chamber or matrigel insert $\left(8 \mu \mathrm{m}\right.$, Corning ${ }^{\oplus}$ BioCoat $^{\mathrm{Tx}}$ Matrigel $^{\circ}$ Invasion Chamber) containing serum-free medium for cell migration or invasion assays, respectively; 20\% FBS in DMEM was added in the lower chamber of the 6-well plate, and cells were incubated for $24 \mathrm{~h}$. The invaded cells in the lower side of the membrane were stained with a Diff-Quick stain, and the number of migrated or invaded cells was counted in different fields.

\section{CRISPR/Cas9-driven MUC5AC gene knockout in colon cell lines}

The genomic deletion of MUC5AC in colon cell lines (HCT-8 and LS174T) was carried out by using CRISPR/ Cas9 vector, pD1401-AD (ATUM, CA, USA), with a specific MUC5AC guide RNA sequence (1st gRNA: 5' CCGAATCCAGCTACAAGCAC-3', 2nd gRNA: 5'TGCCCTCTCTCCTATCGCCC-3'). After 48 h of transfection, single cells were sorted by FACS based on GFP expression into a 96-well plate to obtain MUC5AC knockout (KO) clones. The complete $\mathrm{KO}$ was confirmed by western blotting using anti-MUC5AC antibody.

\section{Isolation of side or stem cell population}

Stem cell or non-stem cell populations were isolated by using ATP-binding cassette inhibitor (verapamil) and DNA staining dye (Hoechst 33342) [17]. Both parental and MUC5AC KO clones were seeded (approximately $1 \times 10^{6}$ cells) and treated with verapamil $(75 \mu \mathrm{M})$. After incubation at $37^{\circ} \mathrm{C}$ for $15 \mathrm{~min}$, Hoechst 33342 dye was added $(5 \mu \mathrm{g} / \mathrm{ml})$ and incubated for $90 \mathrm{~min}$ in the dark, and FACS sorting was carried out. After sorting, stem cell population (SP) cells were seeded in $0.1 \%$ gelatincoated plates containing DMEM-F12 medium along with stem cell growth factors [18], whereas non-stem cell population (NSP) cells were grown in regular DMEM medium as describe above.

\section{Tumor spheroid assay}

Isolated SP from HCT-8 parental or MUC5AC KO clones were seeded (5000 cells/well) in DMEM-F12 with B27 supplement spheroid media [18] in a 96-well lowattachment plate. After 3 days, tumor spheroids of both parental and $\mathrm{KO}$ clones were analyzed.

\section{Immunoprecipitation}

Interaction of MUC5AC and CD44 was assessed by a co-immunoprecipitation assay. Protein A/G plus agarose beads (Santa Cruz Biotechnology, TX, USA) were preincubated with a protein sample $(1 \mathrm{mg} / \mathrm{ml})$ for $1 \mathrm{~h}$ followed by washing and centrifugation. The next day, beads were incubated with MUC5AC antibody $(3 \mu \mathrm{g})$ and IgG isotype control $(3 \mu \mathrm{g})$ along with pre-cleared protein samples at $4{ }^{\circ} \mathrm{C}$ in a rotary shaker for $5-6 \mathrm{~h}$. After that, samples were centrifuged at $3000 \mathrm{rpm}$ for 3 min to remove supernatant, the pellet was washed with RIPA buffer $(4 \times 3 \mathrm{~min})$, and pulldown was assessed using 2\% SDS-agarose gel electrophoresis along with input (3-4\% of the total protein) and IgG control samples in Laemmli buffer. For co-immunoprecipitation, protein samples were resolved in 10\% SDS-PAGE, transferred onto a PVDF membrane, probed with primary antiCD44 antibody, and incubated at $4{ }^{\circ} \mathrm{C}$ overnight after blocking with $5 \%$ non-fat dry milk in PBST. Next, the 
membrane was washed with PBST $(3 \times 10 \mathrm{~min})$, probed with the secondary antibody for $1 \mathrm{~h}$ at $\mathrm{RT}$, and visualized with chemiluminescence ECL reagent. Co-localization of MUC5AC and CD44 was done by immunofluorescence in colon cells (HCT-8 and LS174T) as mentioned in the previous section by using anti-mouse MUC5AC and anti-rabbit CD44 (KO601, Trans Genic Inc. Kobe, Japan) antibodies.

\section{Preparation of MUC5AC-conditioned media}

Both parental and MUC5AC KO cell lines were cultured in DMEM supplemented with 2\% FBS for $48 \mathrm{~h}$. After 48 $h$, conditioned media $(\mathrm{CM})$ was collected and centrifuged at $300 \mathrm{xg}$ for $2 \mathrm{~min}$ to remove cell debris. The supernatant of centrifuged $\mathrm{CM}$ fraction was filtered through a $0.2 \mu \mathrm{m}$ Nylon sterile syringe filter and concentrated using Amicon ${ }^{\circ}$ Ultra $15 \mathrm{~mL}$ Centrifugal Filters (100 kDa NMWL), and MUC5AC KO cells were incubated with CM.

\section{Sandwich ELISA for MUC5AC}

The measurement of MUC5AC concentration before or after CM preparation was done by ELISA. Briefly, MUC5AC (1-13 M1) capture antibody $(2 \mu \mathrm{g} / \mathrm{ml}$ in carbonate buffer) was coated in 96 -well plates $(100 \mu \mathrm{l} /$ well $)$ and incubated at RT overnight. The next day, coated plate was washed twice with PBST, and blocking was done with $3 \%$ BSA for $3 \mathrm{~h}$ at $37^{\circ} \mathrm{C}$. After blocking, the plate was washed three times with PBST, and samples (1:5 dilution) or standards $(100 \mu \mathrm{l} /$ well $)$ were added in triplicate followed by overnight incubation at $4{ }^{\circ} \mathrm{C}$. Then biotinylated detection antibody ( $45 \mathrm{M} 1$, Thermo Fisher Scientific, USA) was added and incubated for $2 \mathrm{~h}$ at RT after washing again with PBST. Next, polymeric streptavidin-HRP was added and incubated for $30 \mathrm{~min}$ at RT. After incubation, freshly prepared $3,3^{\prime}, 5,5^{\prime}$-tetramethyl benzidine (Sigma-Aldrich, Inc., USA) substrate solution was added and incubated for $20 \mathrm{~min}$ in the dark. The enzymatic reaction was stopped by adding 1 $M$ sulfuric acid, and the plate was read at $540 \mathrm{~nm}$.

\section{Cell cycle analysis}

Both parental and KO clones of HCT-8 cell lines $(1 \times$ $10^{6}$ cells) were seeded in serum free media and treated with $\mathrm{IC}_{50}$ of 5 -FU $(5 \mu \mathrm{M})$ for $48 \mathrm{~h}$. After treatments, cells were fixed overnight at $4{ }^{\circ} \mathrm{C}$ in $70 \%$ ethanol. Later, cells were washed with PBS and stained with Telford reagent $(50 \mu \mathrm{g} / \mathrm{mL}$ propidium iodide, $90 \mathrm{mM}$ EDTA, $0.1 \%$ Triton $\mathrm{X}-100$, and $1 \mu \mathrm{g} / \mathrm{mL}$ RNase A) for $1 \mathrm{~h}$ at $4{ }^{\circ} \mathrm{C}$. The DNA content of stained cells were analyzed by using a FACS flow cytometer.

\section{In vivo tumorigenesis}

For tumorigenesis, Scr or Sh5AC $\left(1 \times 10^{6}\right)$ cells in PBS were injected subcutaneously into athymic nude mice (age 5-6 weeks), and every two days tumor volume was measured with a digital caliper. At the end of the study, mice were sacrificed and tumors were resected and weighed. Further, proteins were isolated from both Scrand Sh5AC-pooled tumors and used for western blot analysis. In the case of the orthotopic mouse model, parental and MUC5AC knockout (CRISPR/Cas9) HCT-8 cell lines were infected with firefly luciferase + IRESeGFP Lentifect ${ }^{\text {tw }}$ purified lentiviral particles (GeneCopoeia, MD, USA). After $48 \mathrm{~h}$ transduction, GFP-positive cells were FACS sorted and resuspended in DMEM. Before injecting, luciferase-positive cells were visualized under an IVIS imaging system using D-luciferin (Caliper life sciences, Hopkinton, MA) substrate. For in vivo experiment, $2 \times 10^{6}$ viable cells in PBS were injected into the caecal submucosa of the athymic nude mice after laparotomy in the presence of ketamine/xylazine (87.5 $\mathrm{mg} / 12.5 \mathrm{mg} / \mathrm{kg}$ ) anesthesia. Tumor growth was monitored by bioluminescence imaging using the IVIS system after injecting D-luciferin $(150 \mathrm{mg} / \mathrm{kg})$ intraperitoneally. After imaging several time points, animals were euthanized due to heavy tumor burden in the MUC5ACexpressing group. All the animals were maintained in accordance with guidelines and protocols approved by the Institutional Animal Care and Use Committees (IACUC) of the University of Nebraska Medical Center, Omaha, Nebraska and USA.

\section{Immunohistochemistry}

A tissue microarray (TMA-CO2081) of human colon cancer was purchased from US Biomax Inc. (MD, USA). Tissue slides were baked in the oven at $58^{\circ} \mathrm{C}$ overnight. The next day, slides were cooled to RT and washed using xylene $(4 \times 10 \mathrm{~min})$ to remove paraffin and hydrated through graded alcohol solution $(100,90,70,50,30$, and $20 \%)$ for 10 min each. Further, quenching of endogenous peroxidase activity (3\% $\mathrm{H}_{2} \mathrm{O}_{2}$ in methanol) was carried out by incubation for $1 \mathrm{~h}$ in the dark. It was followed by heat-induced antigen retrieval in $0.01 \mathrm{M}$ citrate buffer in the microwave for $15 \mathrm{~min}$. Next, blocking was done by using 2.5\% horse serum (Impress Reagent Kit, Vector Laboratories, CA, USA) after washing the slides to remove excess citrate buffer. The tissue sections were further incubated with primary antibodies for MUC5AC (45 M1, 1:100 dilutions) and CD44 (1:60 dilutions) at $4{ }^{\circ} \mathrm{C}$ overnight. After washing with PBST $(4 \times 10 \mathrm{~min})$, slides were probed with HRP-labelled universal antimouse/rabbit IgG for $30 \mathrm{~min}$ and then stained with DAB substrate kit (Vector Laboratories, Burlingame, CA, USA). Then slides were counterstained with 
hematoxylin, dehydrated with different graded alcohols followed by xylene washes, and mounted with Permount mounting medium (Fisher Scientific, Grand Island, NY, USA) capped by a coverslip. Composite scoring for MUC5AC was carried by a pathologist and is the product of intensity score and percentage positivity of cells for the given marker. Intensity score for MUC5AC was done on a scale of 0-3 (0-negative, 1-weak, 2-moderate, 3-intense staining) and the percent of positive cells was given on a scale of 1-4 (1: 0-25\%; 2: 26-50\%; 3: 51-75\%; and 4: 76-100\%) [3].

\section{Statistical analysis}

All the data are presented as means with their standard error of the mean (means + SEM). Analyses were performed by using GraphPad Prism Software 7.0 (San Diego, CA, USA). Student t-test were used for two groups, and One-way ANOVA was applied for comparing more than two groups by Tukey's posthoc test. $" p<0.05, " p<0.01$ and ${ }^{* * * *} p<0.001$ were considered statistically significant.

\section{Results}

MUC5AC expression is up-regulated in human colon cancer tissues and cell lines

Our aim was to study whether MUC5AC had a role in colon cancer progression. We initially analyzed The Cancer Genome Atlas (TCGA-COAD) database containing 287 colon cancer and 41 normal samples for MUC5AC expression and observed a significant $(p<0.05)$ upregulation of MUC5AC in colon cancer patients (Fig. 1a). Next, we examined MUC5AC expression in colon TMA, which showed a higher expression of secretory mucin MUC5AC protein in both adenocarcinoma $(n=34, p<$ $0.01)$ and metastatic adenocarcinoma $(n=20, \mathrm{p}<0.01)$ patient tissues (Fig. 1b). To assess the significance of MUC5AC expression in CRC patient survival, publicly available datasets (GEO accession: GSE12945 and GSE17537) were analyzed for MUC5AC expression (http://dna00.bio.kyutech.ac.jp/PrognoScan/index.html).

Kaplan-Meier analysis showed a significant $(p<0.001$ and $p<0.006)$ decrease in overall as well as disease-free survival in patients with high MUC5AC expression, suggesting its tumor-promoting role in CRC (Fig. 1c).

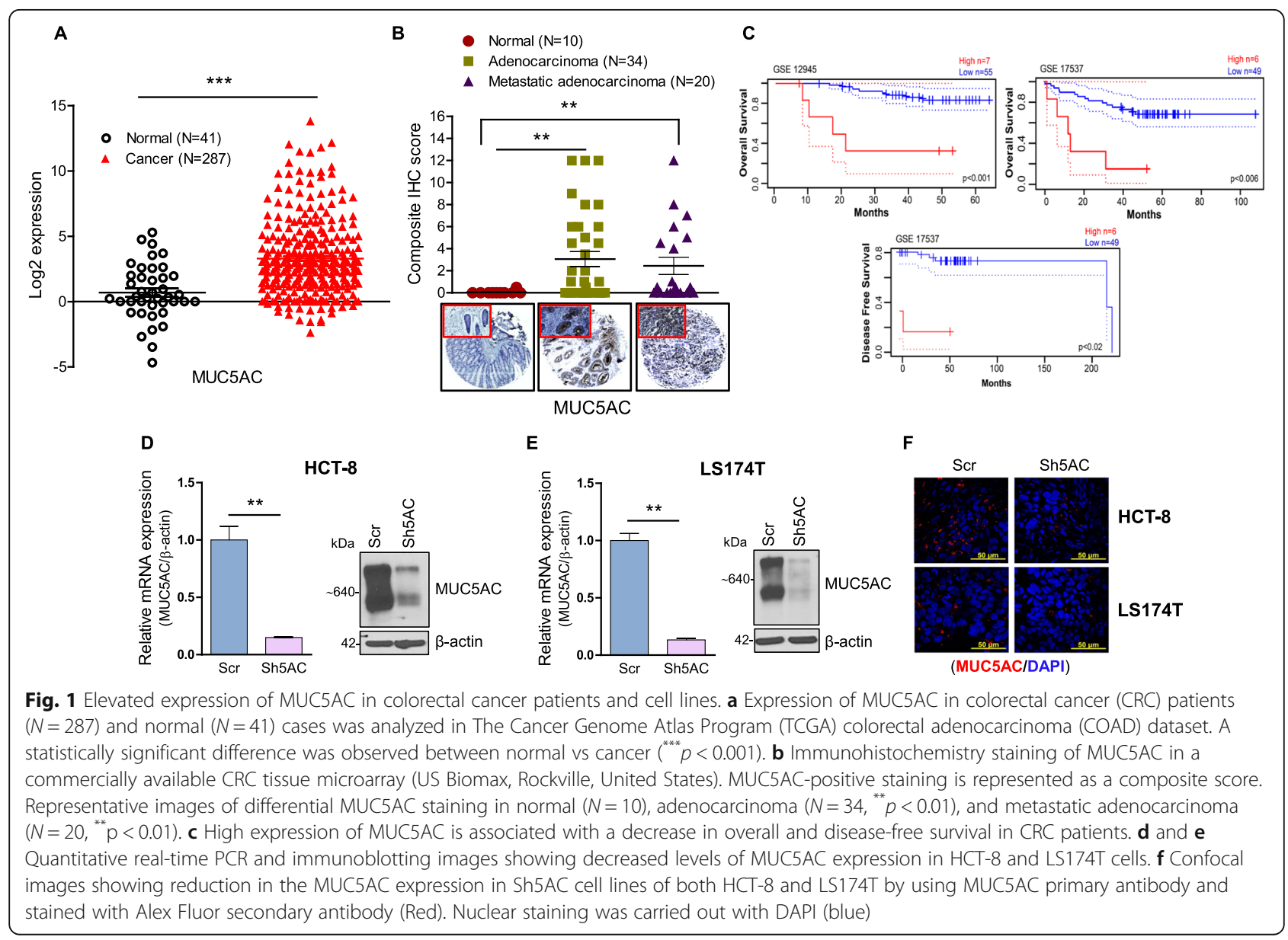


MUC5AC enhances proliferation, invasion, and migration of CRC cells in vitro

Initially, we screened for MUC5AC expression in normal (CCD $841 \mathrm{CoN}$ ) as well as CRC cell lines (HCT-8 and LS174T). Interestingly, we observed higher MUC5AC expression in CRC cell lines as compared to normal cell line (Figure S1A). Next, to study the functional role of MUC5AC in colon cancer progression, endogenous expression of MUC5AC was knocked down in the above mentioned CRC cell lines. The stable knockdown of MUC5AC (Sh5AC) was performed by using the small hairpin RNA system. As shown in Fig. 1d and e, knockdown of MUC5AC in both HCT-8 and LS174T cell lines was confirmed at mRNA and protein levels ( 80-90\%) by qRT-PCR and immunoblot, respectively. Further, we also observed MUC5AC expression by confocal microscopy and confirmed that its expression was reduced in Sh5AC cells as compared to Scr (Fig. 1f). In addition, Sh5AC cells showed less cell proliferation (Figure S1B and $C$ ), invasion, and migration (Figure S1D and E) compared with Scr cells, which suggests that MUC5AC impacts in vitro colon cancer cell growth, migration, and invasion properties.

\section{Isolated cancer stem cells or side population shows higher MUC5AC and CD44 expression}

To understand the molecular mechanism of MUC5AC in CRC progression, we used the CRISPR/Cas9 genetic modification system to delete the MUC5AC gene by designing a specific guide RNAs at exon 2 (Fig. 2a). As shown in Fig. $2 \mathrm{~b}$ and $\mathrm{c}$, complete absence of the MUC5AC protein was observed in two $\mathrm{KO}$ clones by western blotting as compared to parental HCT-8 and LS174T cell lines. Recent studies directly implicate a subset of the population within the tumor, known as stem cells or side population in mediating tumor recurrence and also resistance to chemotherapeutic drugs [19]. Therefore, we isolated SP cells from parental as well as MUC5AC KO clones and observed that the percentage of SP was higher in parental cells $(1.1 \%$ in HCT8 and $7.5 \%$ in LS174T) as compared to $\mathrm{KO}$ clones $(0.7$ and $0.5 \%$ in clones 1 and 2 of HCT-8, and 0.3 and $2.4 \%$ in clones 1 and 2 of LS174T) (Fig. 2d and e). Interestingly, we also observed elevated MUC5AC expression in isolated SP as compared to NSP of the parental cell line (Fig. 3a). Similarly, both parental and KO-SP clones showed higher CD44 expression compared to NSP (Fig. 3a). However, we did not observe down-regulation of other stem cell markers (CD133 and Lgr5) (Fig. 3a), suggesting that both MUC5AC and CD44 have a positive role in maintaining a specific subset of the cancer stem cell population.

The presence of MUC5AC in isolated SP from parental and KO clones of both HCT-8 and LS174T showed distinct morphology as compared to NSP cell lines (Fig. $3 \mathrm{~b}$ and $\mathrm{c}$ ). In addition, we observed a significant increase $(p<0.05)$ in the number of spheres formed in SP of both parental cells as compared to KO clones (Fig. 3d and e), thereby suggesting that MUC5AC helps in maintaining the stemness and colonosphere-forming ability of SP cells.

\section{Secretory MUC5AC mediates CD44 expression}

Conditioned media (CM) was collected from both parental as well as $\mathrm{KO}$ clones and only $\mathrm{KO}$ clones were incubated with this CM for $48 \mathrm{~h}$ (Fig. 4a). As shown in Fig. 4b, before treatment, MUC5AC concentration was significantly enriched in both parental cell lines, as measured by ELISA. After treatment with CM from parental cells, both $\mathrm{KO}$ clones expressed higher CD44 as compared with untreated cells (Fig. 4c). Secondly, to rule out the other factors in CM facilitating CD44 expression, we incubated $\mathrm{KO}$ clones with $\mathrm{CM}$ derived from MUC5AC $\mathrm{KO}$ cells for $48 \mathrm{~h}$. No difference in CD44 expression in the presence or absence of CM (Fig. 4d) was observed, suggesting that secretory MUC5AC has a potential role in modulating CD44 expression.

\section{Physical interactions of MUC5AC with CD44 drives invasion and migration}

The above results suggest a strong correlation between MUC5AC and CD44 expression. Hence, we analyzed the TCGA database containing 275 colon cancer and 41 normal samples for correlation between CD44 and MUC5AC expression (http://gepia. cancer-pku.cn/). Significant up-regulation of CD44 (Fig. 4e) and a strong correlation of MUC5AC with CD44 was observed in CRC patient tissue datasets (Fig. 4f). Next, we observed a strong physical interaction and co-localization between MUC5AC and CD44 by immunoprecipitation and confocal microscopy, respectively in both CRC cell lines (Fig. $4 \mathrm{~g}$ and h). CD44 is a transmembrane glycoprotein involved in several cellular processes like growth, invasion, and migration through Src signaling $[20,21]$. In our study, we observed that knockdown of MUC5AC decreased the expression of cell migration/invasion and survival molecules such as phosphorylated Src, paxillin, integrin- $\beta 4$, and phosphorylated AKT, and increased pro-apoptotic molecules like cleaved PARP and cleaved caspase-9 along with tumor suppressor p53 (Fig. 4i). Transient knockdown of CD44 (siRNA 80 $\mathrm{nM}$ ) in the HCT-8 cell line decreased the expression of down-stream signaling molecules, such as Src and AKT, suggesting that the MUC5AC interaction with CD44 mediated via Src signaling (Fig. 4j). 


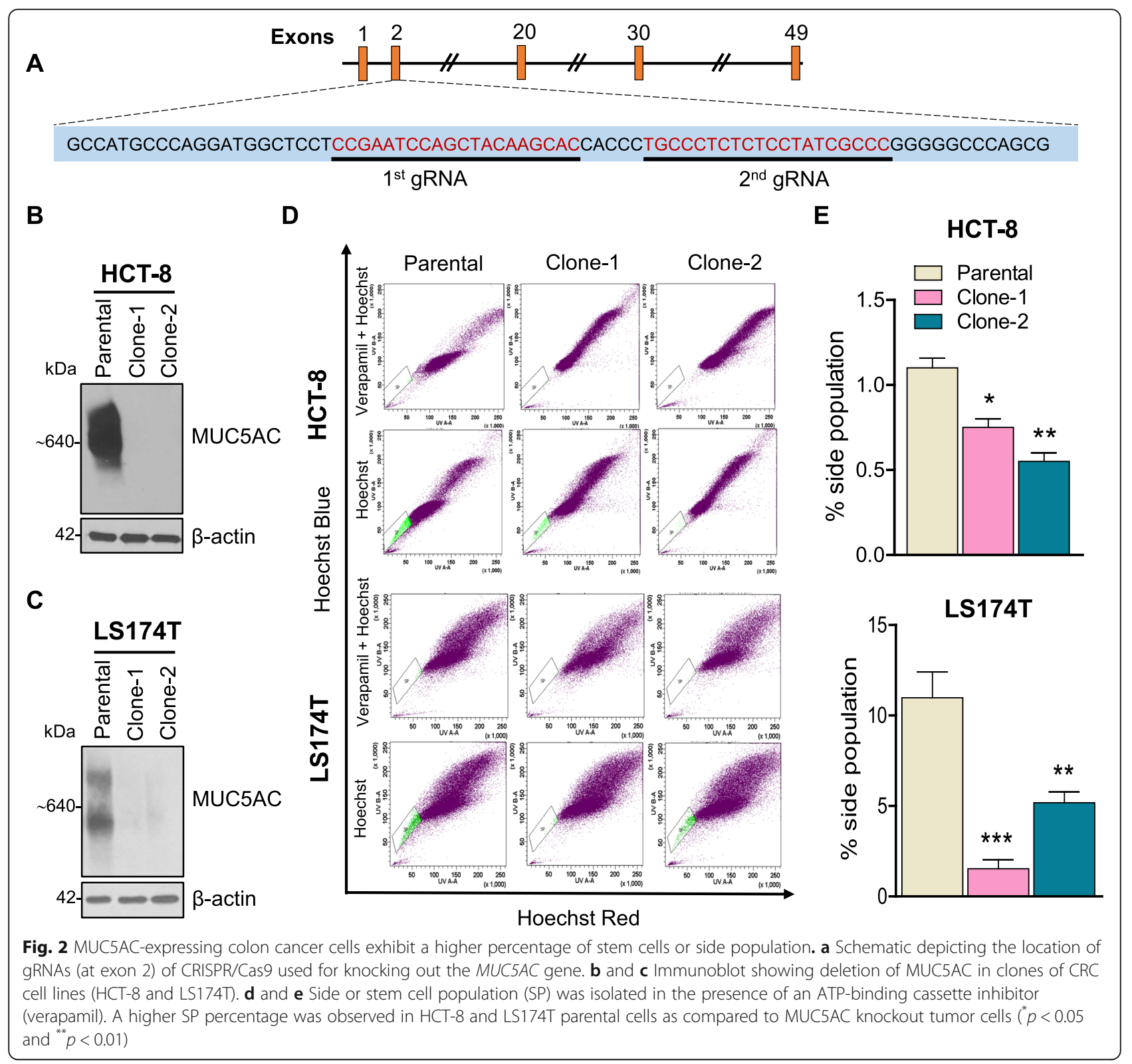

MUC5AC promotes tumorigenesis through the CD44-Srcintegrin axis

Subcutaneous implantation of both Scr and Sh5AC cell lines in the flank region of athymic nude mice induced palpable tumors after 10 days (Fig. 5a). The mice with Scr-MUC5AC cell lines showed a significant increase in tumor volume (Fig. 5b) as well as tumor weight compared to the Sh5AC group (Fig. 5c). Based on western blot analysis, we observed that Sh5AC animals had a lower expression of MUC5AC as compared to the Scr (Fig. 5d). Down-regulation of MUC5AC also reduced CD44 expression and its cell migratory down-stream target Src along with integrin- $\beta 4$ (Fig. 5d). The reduction in CD44 levels in Sh5AC tumors was not as significant as in cell lines, possibly due to the mixed origin of lysate from both tumor and normal epithelial cells. In addition, less tumor growth was observed in the Sh5AC group, which might be partially due to up-regulation of cleaved PARP as an apoptotic marker (Fig. 5d).

\section{Loss of MUC5AC promotes MUC4 expression in CRC}

In our previous study, we demonstrated that MUC4 expression is reduced in CRC cell lines by Notch effector Hath1 through the Wnt/ $\beta$-catenin pathway [22]. Here, we showed that the expression of MUC4 in the TCGACOAD database is significantly down-regulated (Fig. 5e) and a spearman correlation showed a correlation between MUC4 and MUC5AC (http://gepia.cancer-pku. $\mathrm{cn} /$ ) in CRC patients (Fig. 5f). In the current study, both knockdown and $\mathrm{KO}$ of MUC5AC in the HCT-8 cell line showed up-regulation of MUC4 expression (Fig. 5g), and 


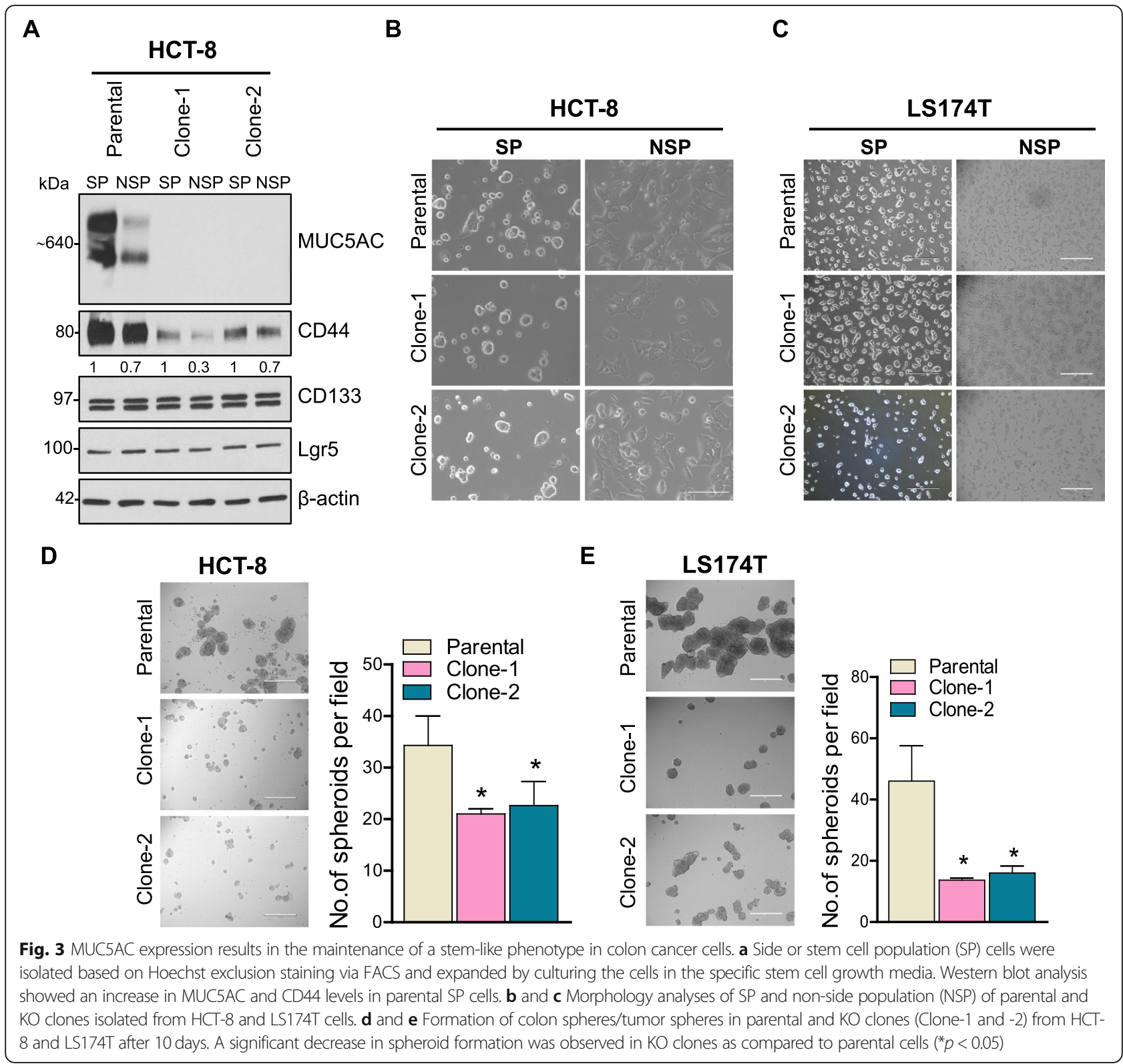

similar results were observed in the subcutaneously injected Sh5AC animal group (Fig. 5h). Nevertheless, the role of MUC4 expression in CRC is still controversial and further studies are needed in this area.

\section{Orthotopic implantation of MUC5AC promotes tumor growth and metastasis}

To study the role of MUC5AC in CRC progression and metastasis, we injected a luciferase-labelled HCT-8 parental as well as MUC5AC KO cell lines in the caecal region of athymic nude mice (Fig. 6a). After 20 days of laparotomy, tumor growth was monitored by an IVIS imaging system after injecting D-luciferin substrate intraperitoneally. Higher tumor burden was observed in the MUC5AC- expressing parental group at both 20 and 50 days as compared to animals bearing $\mathrm{KO}$ cells (Fig. $6 \mathrm{~b}$ and c). During the experimental period, one animal from each group was sacrificed due to heavy tumor burden. Further, the presence of MUC5AC led to more invasive tumors with higher expression of MUC5AC and CD44 in colon tissue (Fig. 6d). Finally, in the presence of MUC5AC, metastatic lesions were observed in the peritoneum, liver, spleen, stomach, and kidney; however, in the $\mathrm{KO}$ group, only peritoneal metastasis was observed (Figure S2).

\section{Presence of MUC5AC mediates resistance to 5-FU}

CRC often recurs in patients because of its drug resistance. Several studies are suggesting that mucins impart 


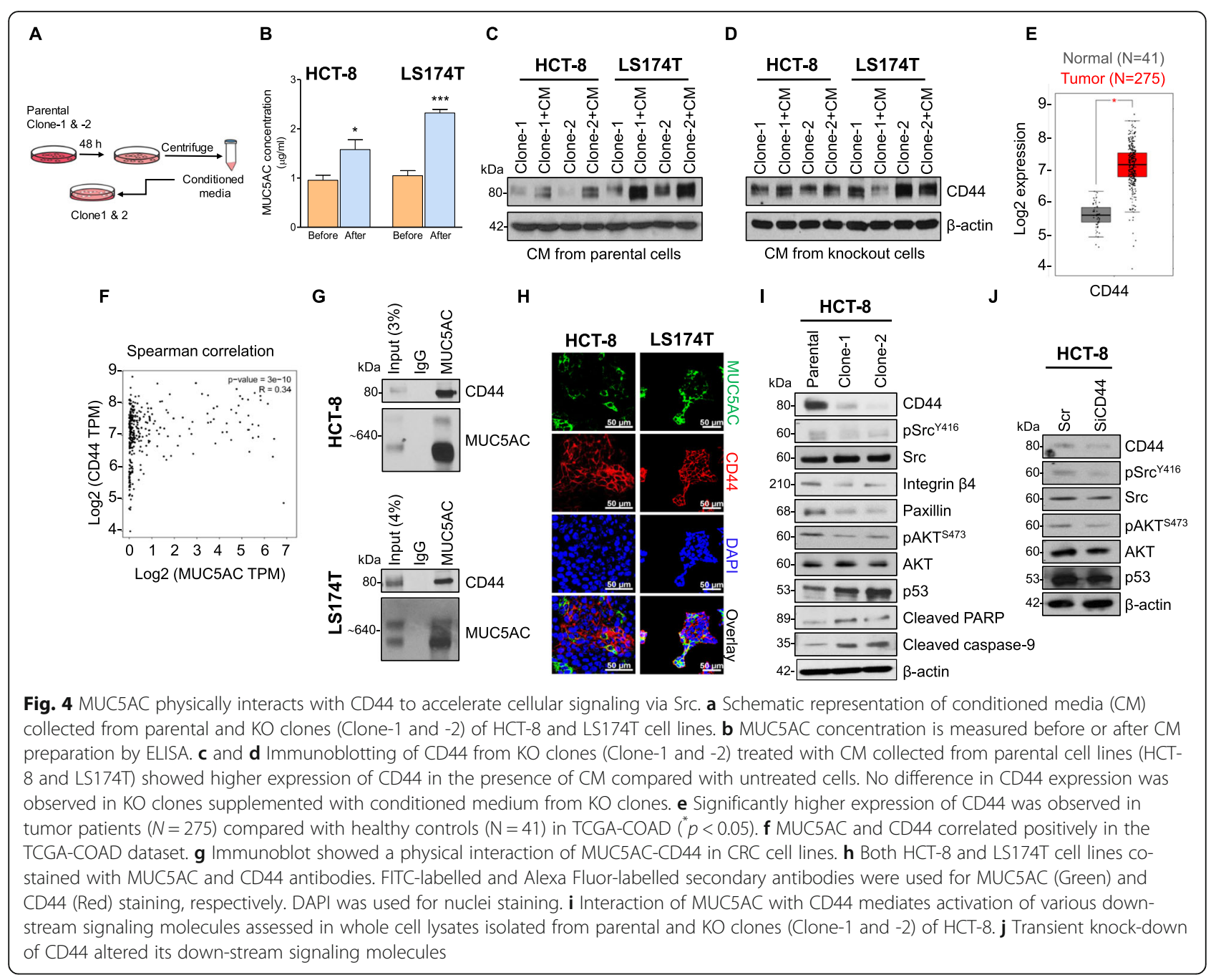

resistance to chemotherapeutic drugs [23-25] by different mechanisms of action, such as physical barrier formation, resistance to apoptosis, drug exclusion, enrichment of stem cells, and epithelial-mesenchymal transition [19]. To determine the role of secretory mucin MUC5AC in CRC chemoresistance, we used 5-FU, which is mostly used for CRC therapy along with oxaliplatin (an alkylating agent widely used for treating advanced CRC in combination with 5-FU). 5-FU and oxaliplatin treatment increased MUC5AC expression in a dose-dependent manner in HCT-8 and LS174T cell lines (Fig. 7a and b). In addition, parental cells expressing MUC5AC showed greater resistance to 5-FU (Figure S3A) and oxaliplatin (Figure S3B), as revealed by significantly higher cell viability in parental cells than $\mathrm{KO}$ clones.

\section{MUC5AC mediates colon cancer chemoresistance through} the $\beta$-catenin/p53/p21 axis

To evaluate the mechanism by which MUC5AC mediates chemoresistance in CRC, we treated the HCT-
8 cell line with 5 -FU $(5 \mu \mathrm{M})$ and observed that $\mathrm{KO}$ clones had higher cell cycle arrest at the G2/M phase (Fig. 7c). To maintain DNA integrity in the presence of a stress condition, p53 activates its down-stream target p21 (WAF1/CIP1) to induce cell cycle arrest [26]. In the present study, treatment with 5-FU in $\mathrm{KO}$ clones induced higher expression of p53 and its target p21 (Fig. 7d). Additionally, due to DNA damage, Chk1 plays an important role in check point activation and mediates p53 activation via the Wnt signaling pathway [27]. Here, we observed that 5 -FU treatment reduced expression of Chk1 in $\mathrm{KO}$ clones and arrested cells at the G2/M phase, which resulted in activation of p53 to induce apoptosis (Fig. 7d). Moreover, 5-FU treatment also up-regulated Wnt ligand co-receptor Lrp6, which induced expression of $\beta$-catenin and its target genes CD44 and Lgr5 (Fig. 7d), suggesting that the presence of MUC5AC facilitates 5-FU resistance via the $\beta$-catenin/p53/p21 axis. 


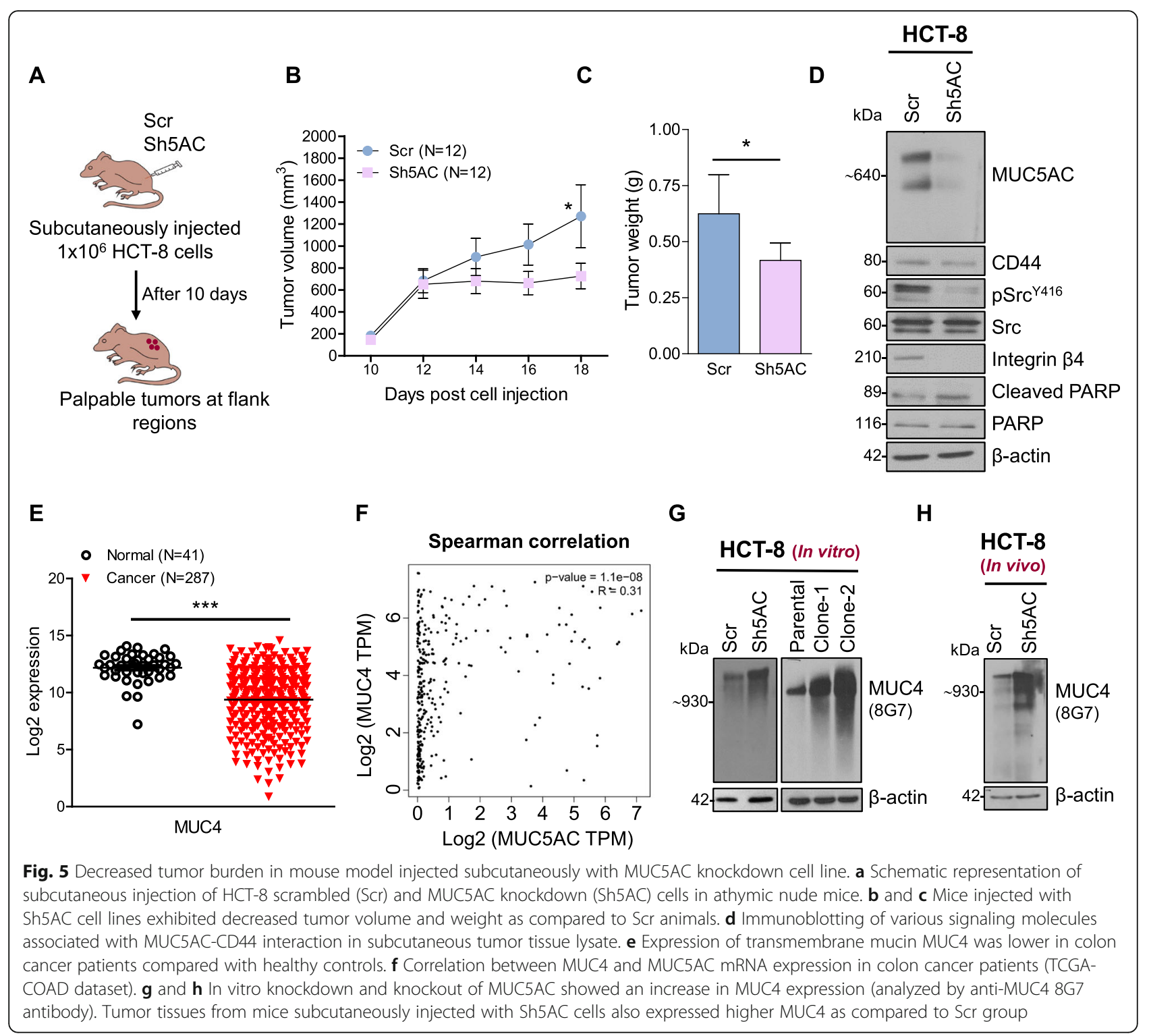

\section{Discussion}

Mucins are implicated in cancer cell behavior and cellular signaling pathways that result in epithelial tumor progression and resistance to chemotherapeutic drugs [19]. Studies have suggested that secretory mucin MUC5AC is overexpressed in several cancers $[9,14,28$, 29 ] and its up-regulation favors progression-free as well as cancer-specific survival of intermediate stages II and III of CRC patients [30]. In addition, MUC5AC enhances pancreatic cancer cell adhesion and invasion potential via up-regulation of integrins, matrix metalloproteinases, and ERK signaling [31]. However, the molecular mechanism by which MUC5AC mediates CRC progression and resistance to chemotherapy is not known. We observed that MUC5AC was overexpressed in CRC patients and cancer cell lines, and its knockdown in CRC cell lines reduced proliferation, invasion, and migratory potential, suggesting that MUC5AC has a tumor promoting role in CRC.

Multiple studies have indicated that mucins mediate chemoresistance through the cancer stem cells (CSCs) population within the tumor. In addition, tumor relapse after therapy might be due to the presence of CSCs because of their self-renewing capacity [19]. Alam et al. (2013) observed that the c-terminal domain of MUC1 up-regulates the breast CSC marker aldehyde dehydrogenase 1A1 (ALDH1A1) through ERK1 and c/EBP on the ALDH1A1 promoter [32]. Moreover, overexpression of MUC4 leads to up-regulation of the CD133 stem cell marker either directly or indirectly via HER2 in ovarian cancer [33]. We also previously observed that downregulation of MUC4 reversed gemcitabine resistance in 
A

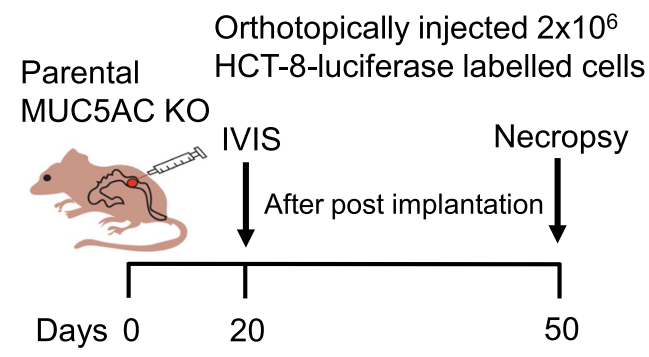

C

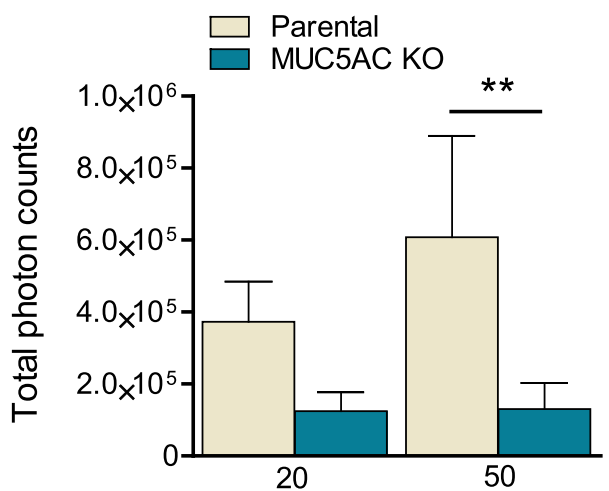

Time after implantation (days)
B

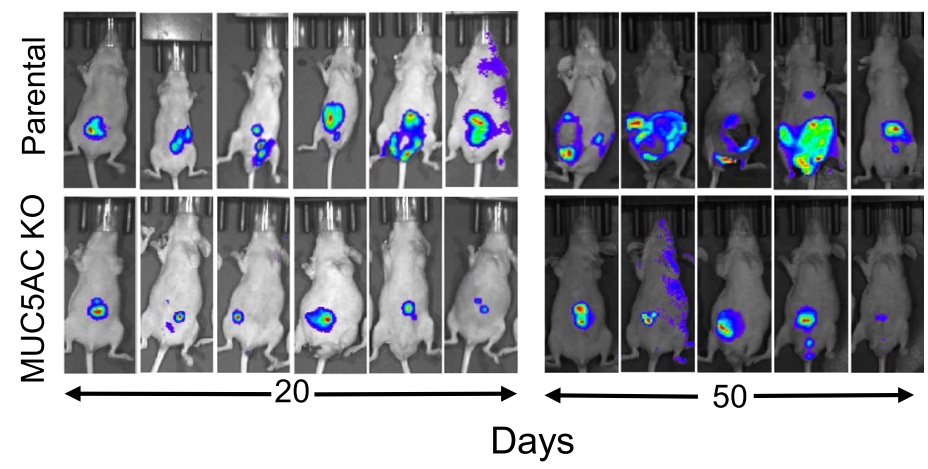

D

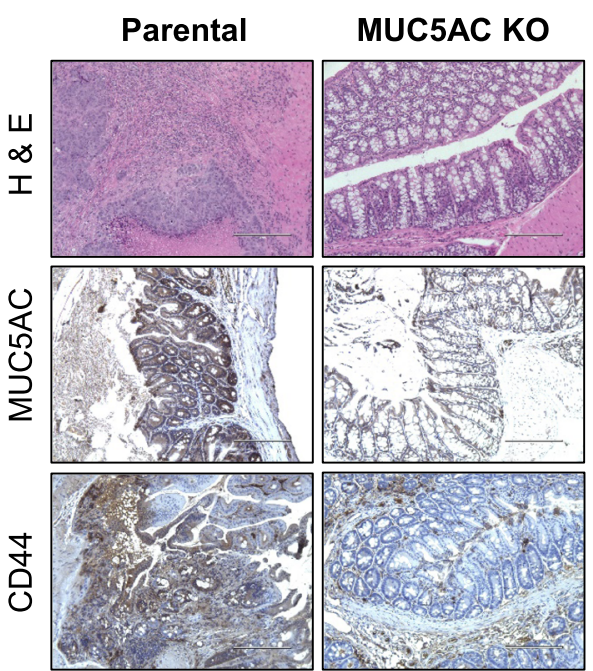

Fig. 6 MUC5AC expression increases tumor burden in orthotopic mouse model. a Schematic representation of colon orthotopic mouse model. Approximately $2 \times 10^{6}$ cells (HCT-8 parental and MUC5AC knockout, labelled with luciferase) were injected in the serosa of the caecal region. $\mathbf{b}$ and $\mathbf{c}$ In vivo tumor growth was imaged using the IVIS imaging system after intraperitoneal injection of D-luciferin (150 mg/kg) at days 20 and 50. Photon counts from both parental and $\mathrm{KO}$ clones were quantified 20 and 50 days post-implantation. $\mathbf{d}$ Representative hematoxylin and eosin stain of parental and $\mathrm{KO}$ cells injected orthotopically in athymic nude mice. Higher tumor burden was observed in the colon of mice injected with parental cells

pancreatic cancer stem/progenitor cells [34]. However, no reports are available to date in the context of MUC5AC's role in the CSCs of CRC. Therefore, to understand the molecular mechanism of MUC5AC in CRC progression, we deleted the MUC5AC gene in CRC cell lines and observed a lower percentage of SP compared with MUC5AC-expressing cells. In addition, the isolated stem cell population overexpressed MUC5AC and CD44. Moreover, our CM experiment also suggested that the presence of MUC5AC in the CRC cell secretome regulates $\mathrm{CD} 44$ expression, which provides a strong relationship between MUC5AC and CD44.

Previously, it was reported that CD44, a transmembrane glycoprotein, is aberrantly expressed in several cancers and regulates cancer cell migration, invasion, and metastasis by interacting with extracellular ligands
[35]. It is also considered an important stem cell marker and is responsible for resistance of tumor cells to drugs [20, 36-38]. Transmembrane CD44 is a non-tyrosine receptor and transmits its signals through the oncogenic protein Src and activation of down-stream effector molecules. Recent study have shown CD44 to regulate breast cancer cell proliferation, migration, and invasion via $\mathrm{Src}$ signaling [21]. Alteration of mucin expression or glycosylation pattern in cancer cells modulates the interactions with other cell surface receptors. The secretory gel-forming mucin MUC5AC may interact with cell surface molecules to mediate cancer progression [39]. We observed that in the TCGA database, CRC patients had an overexpression of CD44 as compared to normal patients, and a positive correlation was observed between MUC5AC and CD44. Furthermore, KO clones expressed 


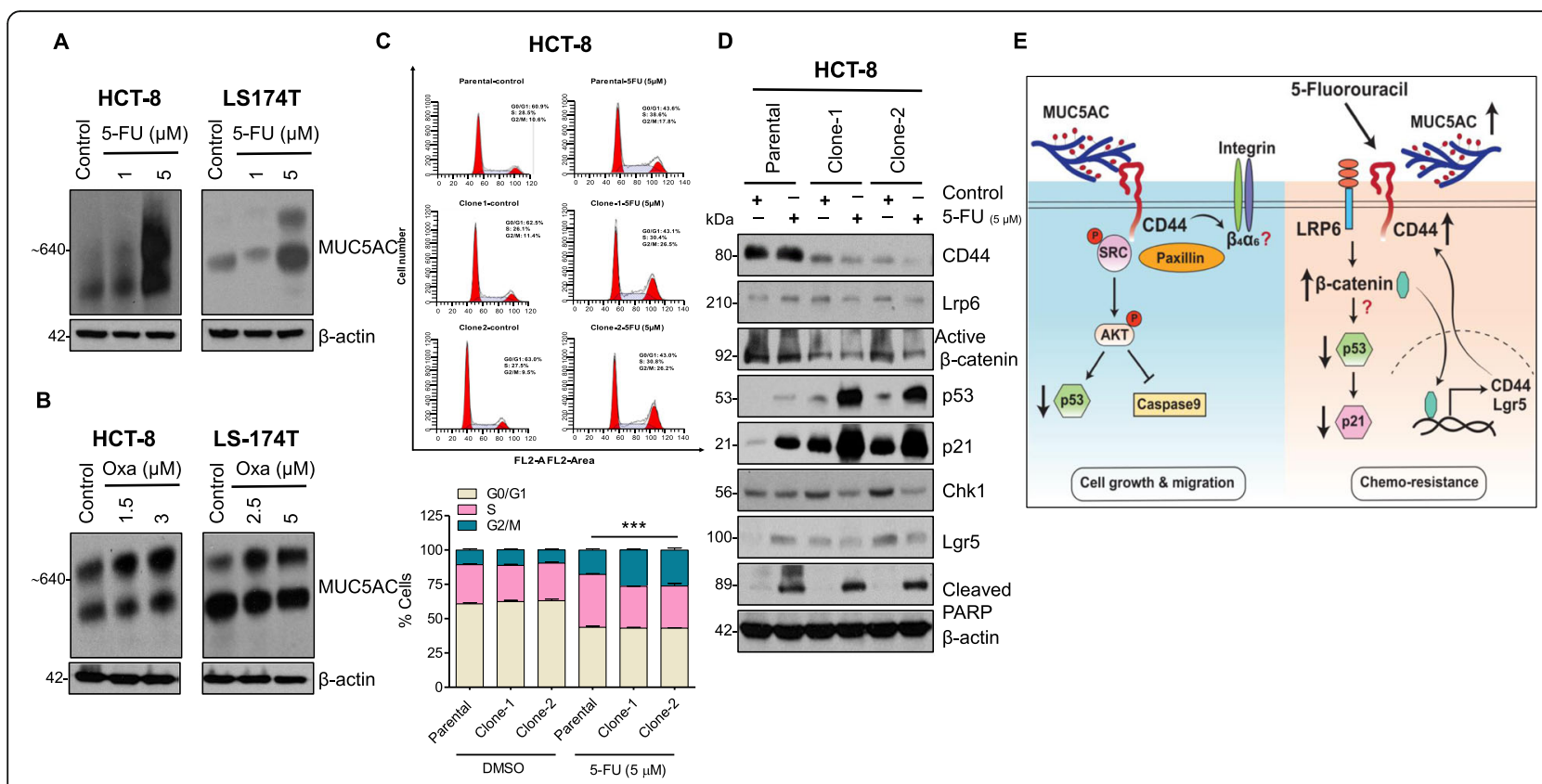

Fig. 7 Presence of MUC5AC mediates resistance to 5-FU. a 5-FU treatment at 1 and $5 \mu \mathrm{M}$ for $48 \mathrm{~h}$ increased expression of MUC5AC in HCT-8 and LS174T cell lines. b Similarly, in the presence of oxaliplatin both cell lines showed upregulation of MUC5AC expression. c DNA content in different phases of the cell cycle was assessed by propidium iodide staining of parental and MUC5AC knockout clones (Clone-1 and -2) followed by FACS analysis. Cell cycle analysis showed that in the absence of MUC5AC, cells were arrested at G2/M phase. $\mathbf{d}$ The presence of MUC5AC facilitates 5FU resistance via the $\beta$-catenin/p53/p21 axis and via upregulation of $\beta$-catenin target genes $L$ gr5 and CD44. e Schematic diagram showing MUC5AC mediates CRC cell survival, migration, and invasion and confers 5-FU resistance via Src and $\beta$-catenin signaling, respectively

less CD44, suggesting a possible association between these molecules. An immunoprecipitation assay demonstrated a physical interaction of MUC5AC with CD44, along with co-localization in CRC cell lines. Additionally, we observed that the interaction of MUC5AC with CD44 impacted CRC migration and invasion via Src, integrin- $\beta 4$, and paxillin signaling. Similarly, our in vivo study also suggested that lower expression of MUC5AC in subcutaneous tumors was associated with downregulation of $\mathrm{CD} 44$. Overall, the study indicated that interaction of MUC5AC-CD44 might be involved in CRC cell migration and invasion.

We previously reported that the transmembrane mucin MUC4 is aberrantly expressed in different cancers [40-42], though its expression in CRC was lost in the adenoma-carcinoma sequence [3]. Additionally, reduced MUC4 expression in CRC was observed by inhibiting Notch effector Hath1 [22]. In the present study, we found that suppressing the expression of MUC5AC in cell lines as well as subcutaneous tumors led to up-regulation of MUC4, which suggested a compensatory role of these two mucins. Interestingly, we also observed that a LS174T cell line expressing very low or no MUC4 had high levels of MUC5AC in it. These studies and others suggest that mucins are useful to distinguish cancer from benign conditions [3]. Similarly, our orthotopic mouse model showed that the presence of MUC5AC enhanced tumor growth and metastasis, as corroborated in previous findings [9, 14, 28, 29].

Currently, targeting mucins in cancer cells is challenging due to resistance to chemotherapeutic drugs $[11,19]$. In the present investigation, CRC cells treated with 5-FU and oxaliplatin expressed higher levels of MUC5AC. In addition, an upregulation of CD44 was also observed in HCT-8 cells upon 5-FU treatment alone. However, the links between MUC5AC and CD44 signaling in response to 5-FU treatment is not known. Previous studies have reported chemotherapeutic drugs targeting the Wnt pathway are gained clinical relevance, however, Wnt/ $\beta$-catenin mediated resistance to drug remains unclear [27, 43]. Our present study showed that treatment with 5-FU increased the MUC5AC and CD44 levels that led to upregulation of Wnt ligand co-receptor, Lrp6. Accumulation of $\beta$-catenin (key component of Wnt pathway) in the nucleus results in the activation of several cell proliferating genes. During cancer, abnormal $\beta$-catenin expression is associated with inactivation of tumor suppressor TP53 gene [44, 45]. Here, we reported that 5-FU dependent down-regulation of $\beta$-catenin resulted an increase in p53 expression and its target gene $p 21$ to cause cell cycle arrest and apoptosis in the absence of MUC5AC. 


\section{Conclusion}

Overall, our findings suggest that secretory mucin MUC5AC has a tumor promoting role via the transmembrane protein CD44 and confers chemoresistance via the $\beta$-catenin/p53/p21 signaling pathway in CRC (Fig. 7e).

\section{Supplementary information}

Supplementary information accompanies this paper at https://doi.org/10. 1186/s12943-020-01156-y.

Additional file 1 : Figure S1. MUC5AC mediates colon cancer cell motility, migration, and invasion. (A) MUC5AC expression was upregulated in human CRC cell lines (HCT-8 and LS174T) as compared to a normal colon cell line (CCD 841 CoN). A549 (lung cancer cell line) was used as a positive control. (B) Cell viability of HCT-8 and LS174T cell lines stably transfected with Scr and Sh5AC was assessed by MTT assay. (C) Colony formation assay showed fewer colonies in Sh5AC cell lines compared with Scr. (D) The presence of MUC5AC in Scr cell lines increased colon cancer migration (by Boyden chamber) and invasion (by matrigel coating). (E) Sh5AC cells exhibited less cell migration than Scr cells in the wound healing assay. Figure S2. Animals with orthotopic implantation of parental MUC5AC cell lines showed different metastatic lesions as compared to knockout group. Figure S3. MUC5AC knockout sensitizes colon cancer cells to 5-FU treatment. (A and B) Cell viability was measured by MTT assay. Bar diagram indicating 5-FU and oxaliplatin treatment for $48 \mathrm{~h}$ significantly decreased cell viability in $\mathrm{KO}$ clones (Clone-1 and -2) compared with parental HCT-8 and LS174T CRC cell lines.

\section{Abbreviations}

5-FU: 5-fluorouracil; CM: Conditioned media; CRC: Colorectal cancer; KO: Knockout; NSP: Non-side population; SP: Side population

\section{Acknowledgements}

We thank Dr. Jessica Mercer for editing this manuscript. We also thank Dr. Gopalakrishnan Natarajan for assisting in the ELISA experiments.

\section{Authors' contributions}

$\mathrm{RP}$ and SKB designed the experiments. RP, SRK, SC, SR, RKN, JAS, IL, KG, $J L C, K M$, and SK performed the study. SKB, SK, and SR supervised the study. All authors read and approved the final manuscript.

\section{Funding}

The authors/work on this manuscript were supported, in part, by grants from the NIH (R01 CA210637, R01CA206444, R01 CA183459, U01 CA200466, P50 CA127297 and P01 CA217798, R41CA213718, and R44 CA224619).

\section{Availability of data and materials}

All data generated or analyzed during this study are included in this manuscript.

\section{Ethics approval and consent to participate}

All animal experiments were approved by the Institutional Animal Care and Use Committee at the University of Nebraska Medical Center, Nebraska, USA.

\section{Consent for publication}

All authors have agreed to publish this manuscript.

\section{Competing interests}

SKB is one of the co-founders of Sanguine Diagnostics and Therapeutics, Inc. Other authors declare no competing interests.

\section{Author details}

${ }^{1}$ Department of Biochemistry and Molecular Biology, University of Nebraska Medical Center, Omaha, NE, USA. ${ }^{2}$ Department of Pathology and Microbiology, University of Nebraska Medical Center, Omaha, NE, USA. ${ }^{3}$ Fred and Pamela Buffett Cancer Center, University of Nebraska Medical Center,
Omaha, NE, USA. ${ }^{4}$ Eppley Institute for Research in Cancer and Allied Diseases, University of Nebraska Medical Center, Omaha, NE, USA.

Received: 2 October 2019 Accepted: 13 February 2020

Published online: 25 February 2020

\section{References}

1. Siegel RL, Miller KD, Fedewa SA, Ahnen DJ, Meester RGS, Barzi A, Jemal A. Colorectal cancer statistics, 2017. CA Cancer J Clin. 2017:67:177-93.

2. Niv $Y$, Rokkas T. Mucin expression in colorectal Cancer (CRC): systematic review and meta-analysis. J Clin Gastroenterol. 2019:53:434-40.

3. Krishn SR, Kaur S, Smith LM, Johansson SL, Jain M, Patel A, Gautam SK, Hollingsworth MA, Mandel $U$, Clausen $\mathrm{H}$, et al. Mucins and associated glycan signatures in colon adenoma-carcinoma sequence: prospective pathological implication(s) for early diagnosis of colon cancer. Cancer Lett. 2016;374:304-14.

4. Reynolds IS, Fichtner M, McNamara DA, Kay EW, Prehn JHM, Burke JP. Mucin glycoproteins block apoptosis; promote invasion, proliferation, and migration; and cause chemoresistance through diverse pathways in epithelial cancers. Cancer Metastasis Rev. 2019;38:237-57.

5. Kang H, Min BS, Lee KY, Kim NK, Kim SN, Choi J, Kim H. Loss of E-cadherin and MUC2 expressions correlated with poor survival in patients with stages II and III colorectal carcinoma. Ann Surg Oncol. 2011;18:711-9.

6. Yonezawa S, Goto M, Yamada N, Higashi M, Nomoto M. Expression profiles of MUC1, MUC2, and MUC4 mucins in human neoplasms and their relationship with biological behavior. Proteomics. 2008;8:3329-41.

7. Hsu HP, Lai MD, Lee JC, Yen MC, Weng TY, Chen WC, Fang JH, Chen YL. Mucin 2 silencing promotes colon cancer metastasis through interleukin-6 signaling. Sci Rep. 2017;7:5823.

8. Krishn SR, Ganguly K, Kaur S, Batra SK. Ramifications of secreted mucin MUC5AC in malignant journey: a holistic view. Carcinogenesis. 2018;39: 633-51.

9. Kaur S, Smith LM, Patel A, Menning M, Watley DC, Malik SS, Krishn SR, Mallya K, Aithal A, Sasson AR, et al. A combination of MUC5AC and CA19-9 improves the diagnosis of pancreatic Cancer: a multicenter study. Am J Gastroenterol. 2017;112:172-83.

10. Khanvilkar K, Donovan MD, Flanagan DR. Drug transfer through mucus. Adv Drug Deliv Rev. 2001;48:173-93.

11. Rao CV, Janakiram NB, Mohammed A. Molecular pathways: Mucins and drug delivery in Cancer. Clin Cancer Res. 2017;23:1373-8.

12. Ahmed D, Eide PW, Eilertsen IA, Danielsen SA, Eknaes M, Hektoen M, Lind $\mathrm{GE}$, Lothe RA. Epigenetic and genetic features of 24 colon cancer cell lines. Oncogenesis. 2013;2:e71.

13. Li HR, Shagisultanova El, Yamashita K, Piao Z, Perucho M, Malkhosyan SR. Hypersensitivity of tumor cell lines with microsatellite instability to DNA double strand break producing chemotherapeutic agent bleomycin. Cancer Res. 2004;64:4760-7.

14. Lakshmanan I, Rachagani S, Hauke R, Krishn SR, Paknikar S, Seshacharyulu P, Karmakar S, Nimmakayala RK, Kaushik G, Johansson SL, et al. MUC5AC interactions with integrin beta4 enhances the migration of lung cancer cells through FAK signaling. Oncogene. 2016;35:4112-21.

15. Moniaux N, Varshney GC, Chauhan SC, Copin MC, Jain M, Wittel UA, Andrianifahanana M, Aubert JP, Batra SK. Generation and characterization of anti-MUC4 monoclonal antibodies reactive with normal and cancer cells in humans. J Histochem Cytochem. 2004;52:253-61.

16. Chaudhary S, Madhukrishna B, Adhya AK, Keshari S, Mishra SK. Overexpression of caspase 7 is ERalpha dependent to affect proliferation and cell growth in breast cancer cells by targeting p21(Cip). Oncogenesis. 2016:5:e219.

17. Vengoji R, Macha MA, Nimmakayala RK, Rachagani S, Siddiqui JA, Mallya K, Gorantla S, Jain M, Ponnusamy MP, Batra SK, Shonka N. Afatinib and Temozolomide combination inhibits tumorigenesis by targeting EGFRvIIICMet signaling in glioblastoma cells. J Exp Clin Cancer Res. 2019;38:266.

18. Nimmakayala RK, Seshacharyulu P, Lakshmanan I, Rachagani S, Chugh S, Karmakar S, Rauth S, Vengoji R, Atri P, Talmon GA, et al. Cigarette smoke induces stem cell features of pancreatic Cancer cells via PAF1. Gastroenterology. 2018;155:892-908 e896.

19. Jonckheere $N$, Skrypek N, Van Seuningen I. Mucins and tumor resistance to chemotherapeutic drugs. Biochim Biophys Acta. 1846;2014:142-51.

20. Chen C, Zhao S, Karnad A, Freeman JW. The biology and role of CD44 in cancer progression: therapeutic implications. J Hematol Oncol. 2018;11:64. 
21. Nam K, Oh S, Lee KM, Yoo SA, Shin I. CD44 regulates cell proliferation, migration, and invasion via modulation of c-Src transcription in human breast cancer cells. Cell Signal. 2015;27:1882-94.

22. Pai P, Rachagani S, Dhawan P, Sheinin YM, Macha MA, Qazi AK, Chugh S, Ponnusamy MP, Mallya K, Pothuraju R, Batra SK. MUC4 is negatively regulated through the Wnt/beta-catenin pathway via the notch effector Hath1 in colorectal cancer. Genes Cancer. 2016;7:154-68.

23. Lesuffleur T, Porchet N, Aubert JP, Swallow D, Gum JR, Kim YS, Real FX, Zweibaum A. Differential expression of the human mucin genes MUC1 to MUC5 in relation to growth and differentiation of different mucus-secreting HT-29 cell subpopulations. J Cell Sci. 1993;106(Pt 3):771-83.

24. Lakshmanan I, Salfity S, Seshacharyulu P, Rachagani S, Thomas A, Das S, Majhi PD, Nimmakayala RK, Vengoji R, Lele SM, et al. MUC16 regulates TSPYL5 for lung Cancer cell growth and Chemoresistance by suppressing p53. Clin Cancer Res. 2017;23:3906-17.

25. Leteurtre E, Gouyer V, Rousseau K, Moreau O, Barbat A, Swallow D, Huet G, Lesuffleur T. Differential mucin expression in colon carcinoma HT-29 clones with variable resistance to 5-fluorouracil and methotrexate. Biol Cell. 2004; 96:145-51.

26. Longley DB, Harkin DP, Johnston PG. 5-fluorouracil: mechanisms of action and clinical strategies. Nat Rev Cancer. 2003:3:330-8.

27. He L, Zhu H, Zhou S, Wu T, Wu H, Yang H, Mao H, Sekharkathera C, Janardhan A, Edick AM, et al. Wht pathway is involved in 5-FU drug resistance of colorectal cancer cells. Exp Mol Med. 2018;50:101.

28. Pereira MB, Dias AJ, Reis CA, Schmitt FC. Immunohistochemical study of the expression of MUC5AC and MUC6 in breast carcinomas and adjacent breast tissues. J Clin Pathol. 2001;54:210-3.

29. Walsh MD, Clendenning M, Williamson E, Pearson SA, Walters RJ, Nagler B, Packenas D, Win AK, Hopper JL, Jenkins MA, et al. Expression of MUC2, MUC5AC, MUC5B, and MUC6 mucins in colorectal cancers and their association with the CpG island methylator phenotype. Mod Pathol. 2013; 26:1642-56.

30. Betge J, Schneider NI, Harbaum L, Pollheimer MJ, Lindtner RA, Kornprat P, Ebert MP, Langner C. MUC1, MUC2, MUC5AC, and MUC6 in colorectal cancer: expression profiles and clinical significance. Virchows Arch. 2016;469: 255-65.

31. Yamazoe S, Tanaka H, Sawada T, Amano R, Yamada N, Ohira M, Hirakawa K. RNA interference suppression of mucin 5AC (MUC5AC) reduces the adhesive and invasive capacity of human pancreatic cancer cells. J Exp Clin Cancer Res. 2010;29:53.

32. Alam M, Ahmad R, Rajabi H, Kharbanda A, Kufe D. MUC1-C oncoprotein activates ERK-->C/EBPbeta signaling and induction of aldehyde dehydrogenase 1A1 in breast cancer cells. J Biol Chem. 2013;288:30892-903.

33. Ponnusamy MP, Seshacharyulu P, Vaz A, Dey P, Batra SK. MUC4 stabilizes HER2 expression and maintains the cancer stem cell population in ovarian cancer cells. J Ovarian Res. 2011;4:7.

34. Mimeault M, Johansson SL, Senapati S, Momi N, Chakraborty S, Batra SK. MUC4 down-regulation reverses chemoresistance of pancreatic cancer stem/progenitor cells and their progenies. Cancer Lett. 2010;295:69-84.

35. Senbanjo LT, Chellaiah MA. CD44: a multifunctional cell surface adhesion receptor is a regulator of progression and metastasis of Cancer cells. Front Cell Dev Biol. 2017;5:18.

36. Mayr L, Pirker C, Lotsch D, Van Schoonhoven S, Windhager R, Englinger B, Berger W, Kubista B. CD44 drives aggressiveness and chemoresistance of a metastatic human osteosarcoma xenograft model. Oncotarget. 2017:8: 114095-108.

37. Hagiwara M, Kikuchi E, Tanaka N, Kosaka T, Mikami S, Saya H, Oya M. Variant isoforms of CD44 involves acquisition of chemoresistance to cisplatin and has potential as a novel indicator for identifying a cisplatin-resistant population in urothelial cancer. BMC Cancer. 2018;18:113.

38. Bourguignon LYW, Earle C, Shiina M. Activation of matrix Hyaluronanmediated CD44 signaling, epigenetic regulation and Chemoresistance in head and neck Cancer stem cells. Int J Mol Sci. 2017;184:1912-19.

39. Hollingsworth MA, Swanson BJ. Mucins in cancer: protection and control of the cell surface. Nat Rev Cancer. 2004;4:45-60.

40. Chaturvedi P, Singh AP, Chakraborty S, Chauhan SC, Bafna S, Meza JL, Singh PK, Hollingsworth MA, Mehta PP, Batra SK. MUC4 mucin interacts with and stabilizes the HER2 oncoprotein in human pancreatic cancer cells. Cancer Res. 2008;68:2065-70.

41. Rachagani S, Macha MA, Ponnusamy MP, Haridas D, Kaur S, Jain M, Batra SK. MUC4 potentiates invasion and metastasis of pancreatic cancer cells through stabilization of fibroblast growth factor receptor 1. Carcinogenesis. 2012;33:1953-64.

42. Ponnusamy MP, Singh AP, Jain M, Chakraborty S, Moniaux N, Batra SK. MUC4 activates HER2 signalling and enhances the motility of human ovarian cancer cells. Br J Cancer. 2008;99:520-6.

43. Kahn M. Can we safely target the WNT pathway? Nat Rev Drug Discov. 2014;13:513-32.

44. Sadot E, Geiger B, Oren M, Ben-Ze'ev A. Down-regulation of beta-catenin by activated p53. Mol Cell Biol. 2001;21:6768-81.

45. Zhang Y, Geng L, Talmon G, Wang J. MicroRNA-520g confers drug resistance by regulating p21 expression in colorectal cancer. J Biol Chem. 2015;290:6215-25

\section{Publisher's Note}

Springer Nature remains neutral with regard to jurisdictional claims in published maps and institutional affiliations.
Ready to submit your research? Choose BMC and benefit from:

- fast, convenient online submission

- thorough peer review by experienced researchers in your field

- rapid publication on acceptance

- support for research data, including large and complex data types

- gold Open Access which fosters wider collaboration and increased citations

- maximum visibility for your research: over $100 \mathrm{M}$ website views per year

At $\mathrm{BMC}$, research is always in progress.

Learn more biomedcentral.com/submissions 